\title{
Prediction of Engineering Development Based on Institutional Approach
}

\author{
Palei T. F. ${ }^{1}$ \\ ${ }^{1}$ Kazan Federal University, 18 Kremlyovskaya St., Kazan, Russian Federation \\ Correspondence: Palei T. F., Kazan Federal University, 18 Kremlyovskaya St., Kazan 420008, Russian \\ Federation. E-mail: kmen555@gmail.com
}

Received: August 1, 2014 Accepted: August 25, 2014 Online Published: November 27, 2014

doi:10.5539/ass.v10n24p120 URL: http://dx.doi.org/10.5539/ass.v10n24p120

\begin{abstract}
The expedience of forecasting the engineering industry development, based on the institutional approach is substantiated, trends, challenges and risks of engineering industry in Russia, including "institutional trap" identified in the article. Engineering industry development scenarios in Russia based on the author's model are considered for the period until 2018. As a tool for building the predictive model the method of correlated-regression analysis is used, as it allows to determine the kind of mathematical functions causation, synthesize diversity of variables in the model and simulate their behavior. The model allows determining the optimal structure and the volume of labor and capital in the future to ensure the growth of sales of engineering products of each species in the national and global market, as well as mechanisms of fiscal and trade policies that maximize the value of sales volumes of engineering industry in Russia.
\end{abstract}

Keywords: forecasting, engineering, industry development, institutional approach, model building

\section{Introduction}

\subsection{Objectives and Scope}

The goal of research is to build a model for forecasting the engineering industry development, based on the institutional approach. Conceptual approaches of forecasting the economic systems development are presented and the necessity and benefits of using the institutional approach are proved; trends in the industry are identified; factors that influence engineering industry development and "institutional traps", impeding the development of engineering in Russia are identified; industry development scenarios based on the formed predictive model are built.

As a tool for building the predictive model the method of correlated-regression analysis is used, as it allows to determine the kind of mathematical functions causation, synthesize diversity of variables in the model and simulate their behavior. In developing the model for forecasting the engineering industry development, based on the institutional approach the following sequence of actions is used:

- Definition of the object, purpose and objectives of the simulation;

- Analysis of the institutional environment factors affecting the development of the various activities of national engineering industry;

- Analysis of industrial factors of the of national engineering industry development activities;

- Selection the basic model of growth;

- Construction of the constraint equations for each activity in engineering by incorporating the basic model of institutional factors;

- Estimation of parameters and approximation of the regression equations;

- Transformation of the regression equations to the predictive model based on system constraints.

The model allows to determine the optimal structure and the volume of labor and capital in the future to ensure the growth of sales of engineering products of each species in the national and global market, as well as mechanisms of fiscal and trade policies that maximize the value of sales volumes of engineering industry in Russia. 


\subsection{Previous Works}

Economics ontology study makes possible to distinguish the characteristics and features of the neoclassical, institutional and evolutionary system and synergistic approaches of forecasting the development of economic systems which are involves the study of various factors determining the development of economic systems in the future, and the assumptions accepted in the forecasting of their development (Table 1).

Table 1. Distinguishing features of the modern methodological approaches of forecasting the development of economic systems

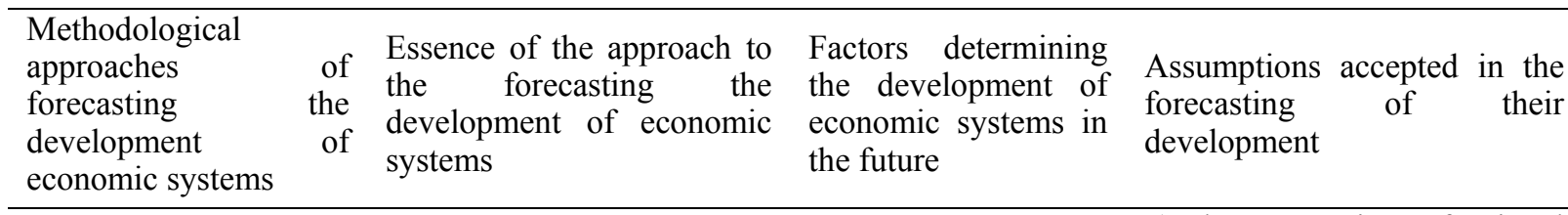

Based on the consideration

The neoclassical of the economy as a system approach in equilibrium, which future development is influenced by factors of production.

Considers the economy as a system, which future development determines by institutional changes.

Evolutionary approach

Considers the economy as a system, which future development is determined by evolutionary processes.

System approach

Synergetic approach

Considers the economy as a complex system, which future development is based on the interaction and impact of subsystems of society.

Economy is treated as a complex system, which future development is
Labor, land, capital and entrepreneurial skills

1) The assumptions of rational behavior of economic agents, perfect competition, etc.

2) Economic growths are determined by the intensity of the accumulation and use of production factors.

1) The assumption about the impact of institutions on the behavior of economic agents.

Institutions

2) Development of the economy is determined by the increase in productivity of factors of production and the improvement of the institutional environment.

1) The assumption is accepted that the development of institutions in the long term is The evolution of determined by its previous institutions and trajectory.

technologies.

2) Development of the economy is determined by the laws of the living systems evolution.

1) The assumption is accepted that the preferences of economic agents are determined by the dynamics Randomness, uncertainty
System tools and resources of society. influenced by the system in which these agents are.

2) The development of economic systems is determined by the laws of the living systems development.

1 The development is presented as a non-linear, multivariate, and irreversible process of alternation of chaos and order.

2 The development of economic systems is spontaneous, unpredictable process. 
The neoclassical approach of forecasting the development of economic systems based on the consideration of the economy as a system in equilibrium, which future development is influenced by factors of production (Lionel, 1968; Solow, 1974).

Institutional approach considers the economy as a system, which future development determines by institutional changes (Nort, 1997; Hayek, 1978; Wilyamson, 1996; Coase, 1993). This approach to forecasting the development of economic systems shifts the focus to determine the exact values of the parameters to identify the development of primarily institutional conditions to achieve them in the future. Evolutionary approach to the forecasting of economic systems considers the economy as a system, which future development is determined by evolutionary processes (Sopin, 2009). Systemic approach considers the economy as a complex system, which future development is based on the interaction and impact of subsystems of society. (Kleiner, 2008) In contrast to the evolutionary and systematic approaches synergetic approach denies the genetic nature of the changes, based on the idea of development as a nonlinear, multivariable and irreversible process (Muravyov et al., 2013). Within the framework of the synergetic approach economy is treated as a complex system, which future development is determined by the dynamics of order and chaos.

Neoclassical, institutional and systemic approaches direct us to research the optimal ratio of factors that ensure the development of the economy in the future, so they can be used to develop normative expectations. Neoclassical and institutional approaches are appropriate to apply for regulatory development, and searching for the short and medium-term forecasts. It is impractical to use these approaches for predicting the evolutionary processes because they are not focused on the study of latent factors determining the economic system development in the long run, which becomes possible if applying an evolutionary, system and synergistic approaches.

\subsection{The Proposed Distinguishability Based on Institutional Approach}

The necessity of predicting the engineering industry development according to institutional approach is due to specific institutional features of engineering as industry sector and objectively folding processes of change of the world economy, which are the following:

- Increasing the regulatory role of the state in the national economy in the condition of a post-industrial technological system;

- Direct involvement of the state in regulating a number of engineering sectors, in particular relating to the military-industrial complex;

- Increased competition among countries in a transnationalization of the world economy.

Engineering development in modern conditions is mediated by the influence of the transition to a post-industrial technological system, characterized by the properties of the global, information, service and sustainability. The growth of uncertainty and contradictory socio-economic development of the economy increases the risk to investors, which increases the value of active state intervention to economic development engineering (Safiullin et al., 2012). Institutional approach provides the possibility of assessing the effectiveness of legal constraints in the economy, affecting the development of engineering in the future, it is important to select the areas of industrial policy. Besides, institutional approach provides the models that reveal the mechanism of social and psychological motivation of economic agents, which should be taken into account in the organization of interaction of the contracting authority and engineering enterprises in the future. States compete to attract transnational companies' investment resources into its territory, using the conditions of the institutional environment as a factor contributing to attract investors (Safiullin et al., 2013). Institutional approach allows modeling the dynamics of economic growth within the constraints of mechanical engineering, focusing researchers' attention on qualitative changes of the institutional environment that determine its development (Palei, 2014).

The research of trends in the engineering industry development in Russia and abroad suggests the problems and risks impeding its development and identifies the following negative features:

- Increasing competition in the national and foreign markets;

- Inertial technological development of national engineering;

- Growth of the share of foreign producers in the sales of national engineering products;

- Slowing of growth in the market capitalization of the largest domestic engineering companies;

- Decrease in the efficiency of production of domestic engineering. 
The necessity of the development of forecasting modern methods of the engineer industry development in order to its adequately managing is obvious.

\section{Materials and Methods}

To investigate the influence of institutional factors on the development of Russian engineering industry volume of shipped goods of own production, works and services in-house engineering were used as indicators and indicators used in the calculation of the Index of Economic Freedom by Heritage Foundation (IEF), 2005-2011. (The Heritage Foundation, 2012).

Table 2. The evaluation of the coupling strength between the indicators IEF Heritage Foundation and the development of engineering in magnitude to Spearman correlation coefficient

\begin{tabular}{ll}
\hline Indicator & Spearman correlation coefficient \\
\hline Index of Economic Freedom & 0,487 \\
Business Freedom & 0,464 \\
Foreign trade Freedom & $0,857^{*}$ \\
Fiscal Freedom & 0,357 \\
Freedom from government interference & $-0,991^{*}$ \\
Monetary Freedom & 0,453 \\
Investment Freedom & 0,359 \\
Financial Freedom & 0,393 \\
Property rights protection & 0,160 \\
Freedom from corruption & 0,342 \\
\hline
\end{tabular}

* Correlation coefficient is significant at 5\% level. This template has been tailored for output on the custom paper size $(21 \mathrm{~cm} \times 28.5 \mathrm{~cm})$. The margins are set as follows: top $=25 \mathrm{~mm}$, bottom $=30 \mathrm{~mm}$, right $=20 \mathrm{~mm}$, left $=20 \mathrm{~mm}$, space between column $=75 \mathrm{~mm}$. The paragraphs must be indented. All paragraphs must be left justified and right justified.

\section{Results and Discussion}

The results of assessing the strength of the link between indicators of IEF Heritage Foundation and the development of engineering industry in Table 1 indicate a high correlation of mechanical engineering and development indicators such as IEF freedom of foreign trade, freedom from government interference. Indicator of freedom from government intervention associated with the share of public expenditure in GDP affects the development of mechanical engineering. Consequently, the development of mechanical engineering is closely associated with the variables of economic freedom, which express the influence of economic mechanisms of investment, operating in the country.

The influence of freedom of trade on engineering industry development shows the competition institute action in the economy, stimulating both national enterprises to develop in conditions of expansion of multinational companies and multinational companies to expand markets.

On our opinion, the process of institutional transformation affected adversely on the development of engineering, which took place in Russia in the post-perestroika period. We identified the main "institutional trap", impeding the development of national engineering industry.

Table 3 presents the main "institutional trap", impeding the development of the domestic engineering industry, which are combined according to their type in the two groups: industry-based and specific.

Table 3. Main "institutional trap", impeding the development of the domestic engineering industry in Russia

\begin{tabular}{ll}
\hline Types of "institutional trap" & Variety of "institutional trap" \\
\hline & The trap of development catch-up model selection \\
Tndustry-based & The trap of short horizon of strategic planning \\
& The trap of restriction on the use of refinancing mechanism \\
Specific & Corruption in the system of state orders placement \\
\hline
\end{tabular}


The trap of selection catch-up model of development hinders the development of sectors and activities engineering, bearing new (sixth) technological system, and accordingly, its technological development in general The trap of short horizon of strategic planning is an obstacle to the development of public-private partnership in Russia and attracts domestic investors in engineering. Limiting the use of the trap mechanism prevents effective refinancing borrowings for development and modernization of domestic engineering. The trap of inefficient owner and inefficient management has a negative impact on the efficiency of business management engineering. Corruption in the system of state orders placement is a growth driver in transaction costs, which negatively affects the development of mechanical engineering (Bagautdinova, 2013). We propose to consider the identified institutional traps when developing engineering development forecasts and promotes the institutional environment formation of the state.

In our opinion, for the approximation of forecasts of engineering in Russia to the economic realities, it is advisable to develop and use predictive models based on the institutional approach.

The method of correlation and regression analysis used as a forecasting models' development toolkit, as it allows to determine the kind of mathematical functions causation, synthesize different variables in the model and simulate their behavior. In the evolution of the engineering development forecasting model, based on the institutional approach, the following sequence of actions is used:

- Definition of the object, purpose and objectives of the simulation;

- Analysis of the institutional environment factors affecting the development of the various activities of domestic engineering;

- Analysis of production factors in the development of domestic engineering activities;

- Selection of the basic model of growth;

- Construction of the constraint equations for each activity in engineering by incorporating of the institutional factors in the basic model;

- Estimation of the parameters and the adequacy of the regression equations;

- Transformation of the regression equations in the prediction model based on a system of constraints.

Model for the development forecasting of Russian engineering industry in expanded form is a system of constraints:

$$
\begin{aligned}
& \left\{Y=1.93 \cdot e^{-0.002 \cdot I G S+0.004 \cdot I F T} \cdot K_{1}^{0.763} \cdot L_{1}^{0.507}+1.73 \cdot e^{-0.008 \cdot I G S+0.002 \cdot I F T} \times\right. \\
& K_{2}^{0.588} \cdot L_{2}^{0.723}+1.61 \cdot e^{-0.011 \cdot I G S+0.007 \cdot I T F} \cdot K_{3}^{0.503} \cdot L_{3}^{0.739} \\
& I G S_{\text {onm }} \leq I G S \leq 1 \\
& 0 \leq I F T \leq 1 \\
& Y \rightarrow \max
\end{aligned}
$$

Where $Y$ : the volume of shipped own-produced goods, executed works and services by their own engineering resources (at current prices), bln rub.;

$K_{1}, K_{2}, K_{3}$ : investment in fixed assets of organizations producing machinery and equipment; electrical, electronic and optical equipment; vehicles and equipment, bln rub.;

$L_{1}, L_{2}, L_{3}$ : the average number of employees of organizations producing machinery and equipment; electrical, electronic and optical equipment; vehicles and equipment, '000 People

$I G S$ : the index of freedom from government interference (Index of Economic Freedom Indicator), calculated by the Heritage Foundation for the Russian Federation;

ITF: Freedom Index Foreign Trade (Index of Economic Freedom Indicator), calculated by the Heritage Foundation for the Russian Federation.

Restraints in the model are the limiting values of the maximum possible degree of freedom of doing business (ITF index is measured from 0 to 1 ); resource restraints on the maximum possible freedom from government intervention based on the size of the budget (the index is limited to the optimum value IGS $_{\text {opt }}$, below which the budget deficit appears). The restraints are limiting values of the maximum possible degree of freedom of doing business (ITF index is measured from 0 to 1); resource constraints on the maximum possible freedom from government intervention based on the size of the budget (the index is limited to the optimal value IGS $_{\text {opt }}$, below 
which there is a budget deficit appears).

The objective function of the model is to maximize the volume of dispatched goods of own production, executed works and services by own forces of mechanical engineering.

The mechanism of the model is to reflect the dependence of sales volumes of engineering in Russia for a specific period on the number of inputs (labor and capital in engineering) and institutional determinants (degree of state intervention and the freedom of foreign trade). In this model, the specific directions of the state budget and foreign trade policy in varying degrees affect the development of engineering activities. Thus, the model allows taking into account changes in the budget and foreign trade policy in developing forecasts of engineering.

\section{Conclusion}

In the context of Russia's accession to the WTO forecast impact assessment the state budget and foreign trade policy on engineering in Russia is of interest. With the use of predictive models (1) two scenarios of engineering in Russia up to 2018 is developed-inertial and active investment.

Inertial scenario is characterized by a slowdown in the national engineering industry until 2018 if current macroeconomic policy is saved. Investment-active scenario is characterized by moderate growth in the forecast period of mechanical engineering in the case of government increases investment in the industry.

Based on this forecast, we can conclude that the effect of the positive impact of the Institute of competition due to the reduction of tariff and non-tariff restrictions on foreign trade does not provide a significant growth. Decrease in the degree of state intervention in the economy, associated with a decrease in the share of public spending in GDP, a negative impact on the development of engineering and will slow down its development.

In our opinion, Russia's accession to the WTO will not allow radically change the situation in the national engineering industry, if the mechanism of state regulation are not changed.

\subsection{Future Work}

Based on the study, the performance, characteristics and the accuracy of the feature selection model, there are still possibilities to advance the performance of the proposed model by the further refinement of the industry development forecasts on the basis of logically-probabilistic modeling scenario conditions of development with regard to risks associated with changes of the methods and tools of state regulation. The results of this study are in the hands of the future researchers.

\section{References}

Bagautdinova, N. G., Goncharova, I. V., Shurkina, E. Y., Sarkin, A. V., Averyanov, B. A., \& Svirina, A. A. (2013). Entrepreneurial development in a corrupted environment. Procedia Economic and finance, 5, 73-82. http://dx.doi.org/10.1016/S2212-5671(13)00012-9

Bagautdinova, N. G., Nayda, A. M., Hayrullin, B. A., \& Arzhantseva, N. (2014). Behaviour of Households on Financial Investments Market. Mediterranean Journal of Social Sciences, 5(12), 103-106.

Fakhrutdinova, E. V., Kolesnikova, J. S., Suleimanov, T. D., \& Khalikov, A. L. (2014). The interrelation of the problems of the youth labour market and the "brain drain". Life Science Journal, 11(6s), 473-477.

Ismagilova, G. N., Safiullin, L. N., \& Bagautdinova, N. G. (2014). Tourism development in region based on historical heritage. Life Science Journal, 11(6s), 63-367.

Karasik, E., Yagudin, R., Leukhin, A., \& Zagidullina, V. (2014). Improvement of social policy towards the disabled in the Russian Federation. Life Science Journal, 11(6s), 478-481.

Khadiullina, G. N., Bagautdinova, N. G., Shevko, N. R., \& Pratchenko, O. V. (2014). Condition and Development Characteristics of The Russian Market of Information Technologies. Mediterranean Journal of Social Sciences, 5(12), 21-26.

Kleiner, G. B. (2008). System paradigm and the system management. Russian Management Journal, 6(3), 27-50.

Lionel, Ch. R. (1968). The Theory of Economic Development in the History of Economic Thought (p. 405). New Jersey: Princeton University Press.

Muraviev, V. A., Gryaznova, A. G., \& Dumnaya, N. N. (2004). In search of a new theory (p. 354). Moscow: KnoRus.

Palei, T. F., \& Kornilova, A. U. (2014). Management of institutional factors of economic development. Актуальні проблеми економики=Актуальные проблемы экономики, 3, 38-45. 
Panasyuk, M. V., Pudovik, E. M., \& Sabirova, M. E. (2014). Problems of labor market of modern Russia in conditions of stable economic growth. Life Science Journal, 11(6s), 487-489.

Safiullin, L. N., Gafurov, I. R., Shaidullin, R. N., \& Safiullin, N. Z. (2014). Socio-economic development of the region and its historical and cultural heritage. Life Science Journal, 11(6s), 400-404.

Safiullin, M. R., Ankudinov, A. B., \& Lebedev, O. V. (2013). Research into the motives and factors of investment activities of enterprises (by the example of companies in the Volga Federal District) Studies on Russian Economic Development, 24(4), 385-393. http://dx.doi.org/10.1134/S1075700713040114

Safiullin, M. R., El'shin, L. A., \& Shakirova, A. I. (2012). Evaluation of business and economic activity as a short-term forecasting tool Herald of the Russian Academy of Sciences, 82(4), 290-294. http://dx.doi.org/10. 1134/S1019331612040053

Sarkin, A. V., Bagautdinova, N. G., Averyanov, B. A., \& Arzhantseva, N. (2014). The Concept of "New" Paternalism and Its Realization within the State Regulation of Economy. Mediterranean Journal of Social Sciences, 5(12), 27-32.

Sarkin, A. V., Bagautdinova, N. G., Averyanov, B. A., Novenkova, A. Z., \& Arzhantseva, N. (2014). Assessment of Efficiency of Realization of Paternalistic Policy of Industrial Enterprises Development. Mediterranean Journal of Social Sciences, 5(12), 9-14.

Solow, R. M. (1974). Intergenerational Equity and Exhaustible Resources. Rev. Econ. Stud., 64(3).

Sopin, V. S. (2009). An evolutionary theory of economic science: Problems and prospects. Problems of modern Economics, 3. Retrieved from http://www.m-economy.ru/art.php?nArtId=2687

Svetunkov, S. G., \& Svetunkov, I. S. (2010). Methods of socio-economic forecasting (p. 147). SPb: SPbGUEF.

The Heritage Foundation. (2012). Index of Economic Freedom. Retrieved from http://www.heritage.org/index/

\section{Copyrights}

Copyright for this article is retained by the author(s), with first publication rights granted to the journal.

This is an open-access article distributed under the terms and conditions of the Creative Commons Attribution license (http://creativecommons.org/licenses/by/3.0/). 